\title{
NARRATIVA COM O MITO SACI PERERÊ: DOS ASPECTOS TEÓRICOS À PROPOSTA DE TRANSPOSIÇÃO DIDÁTICA
}

Idelma Maria Nunes PORTO

UEL

Alba Maria PERFEITO

UEL

Resumo: O presente artigo integra os estudos do Projeto de pesquisa em Lingüística Aplicada - de cunho etnográfico - "Escrita e ensino gramatical: um novo olhar para um velho problema" que focaliza a formação do professor de língua portuguesa, via diagnóstico e intervenção, por meio da reflexão teórico-prática, visando ao aprimoramento do processo de ensino-aprendizagem de língua materna, sobretudo, no que se refere à análise lingüística. Nesse contexto, as discussões têm considerado o gênero discursivo como objeto de ensino - eixo de articulação e progressão curricular - e o texto, como unidade de significação e ensino - elemento integrador das práticas de leitura, de análise lingüística e de produção textual. O objetivo fundamental do artigo em pauta é o de analisar uma narrativa com o mito Saci Pererê, a partir das marcas lingüístico-enunciativas, em relação às condições de produção (suporte, interlocutores, finalidade e local de circulação), ao tema e à construção composicional, no processo de construção de possíveis efeitos de sentido. E, então, apontar sugestões, em uma seqüência didática, a fim de contribuir de maneira teóricoprática com estudos relacionados ao processo de ensino-aprendizagem de língua materna.

Palavras-chave: leitura, análise lingüística, narrativa, mito, seqüência didática.

Abstract: The present article integrates the studies of the research Project in applied Linguistics - of ethnographic stamp - "Writing and grammatical teaching: a new look for an old problem" that focalizes Portuguese teacher's formation through diagnosis and intervention, through the reflection theoretical-practice, the refinement of process teaching-learning of mother language, above what it refers to the linguistic analysis. In that context, the discussions have been considering 
the discursive genre as a teaching object - articulation axis and curricular progression - and the text, as a unit of meaning and teaching - integration element of reading practices, linguistic analysis and textual production. The aim in this paper is to analyze a narrative with the myth "Saci Pererê", of narrating order, starting from linguistics-enunciation marks in relation to the production conditions (supports, speakers, purpose and circulation place), the theme and the compositional construction, in the process of possible sense effects, and pointing work suggestions, in a didactic sequence, in order to contribute in a theoretical-practical way with the studies related to the process of teaching-learning of mother language.

Keywords: reading, linguistic analysis, narrative, myth, didactic sequence.

Resumen: Este trabajo forma parte de los estudios realizados en el Proyecto de investigación en Lingüística Aplicada - de recorte etnográfico - titulado "Escrita e ensino gramatical: um novo olhar para um velho problema" que está centrado en la formación del profesor de lengua portuguesa, a traves de la diagnosis e de la intervenctión, com base en la reflexión teórico-prática, com el objetivo de rentabilizar el proceso de enseñanza-aprendizaje de lengua materna, especialmente en lo referente al análisis lingüístico. En ese contexto, las discusiones han considerado el género discursivo como objeto de enseñanza - eje de articulación y de progresión curricular - y el texto como unidad de significación y enseñanza - elemento integrador de las práticas de lectura, análisis lingüístico y producción textual. El objetivo de este trabajo es analizar una narrativa com el mito "Saci Pererê", especialmente las marcas lingüístico-enunciativas, que dicho texto contiene, en relación a las condiciones de producción (suporte, interlocutores, finalidad, lugar de circulación), el tema, y la construcción composicional, en el proceso de construcción de efectos de sentido. Y, de esa forma, indicar sugerencias, en uma secuencia didáctica, com la finalidadade de apontar, de maneira teórico-prática, a los estúdios relacionados al proceso de enseñanza-apendizaje de lengua materna.

Palabras claves: leyendo, análisis lingüístico, mito, secuencia didáctica 


\section{Introdução}

Travaglia (2000) já preconizava, como proposta de ensino de gramática, a inter-relação das concepções de linguagem com os enfoques gramaticais (gramática de uso, reflexiva, teórica e normativa) em atividades, de modo capaz de desenvolver a competência comunicativa do aluno e outras habilidades, tais como o raciocínio científico, e principalmente a habilidade lingüística, que lhe desse condições de trabalhar a língua e de utilizá-la nas mais variadas situações.

Geraldi (2003), por sua vez, não utiliza o termo gramática, mas análise lingüística, considerando três atividades efetivas em sala de aula, as lingüísticas, epilingüísticas e metalingüísticas, e propõe o trabalho com operações discursivas como atividades de formulação textual.

Em outra fase, o advento dos PCNs (BRASIL, 1997 e 1998) passa a considerar o texto como unidade de ensino, baseando-se em noções bakhtinianas. Então, começam a emergir estudos relativos aos gêneros discursivos e ao processo de ensino-aprendizagem de Língua Portuguesa. Nesse sentido, trabalhos fundamentados nas pesquisas de Dolz e Schneuwly (1996), Barbosa (2003) e Bronckart (1999) passam a frutificar.

Em nossa caminhada, com fundamentação da Lingüística Aplicada (MOITA LOPES, 2000; CELANI, 2000; entre outros), sobre a formação continuada de professores, no projeto "Gramática e Ensino Gramatical", as discussões progrediram no aspecto de compreendermos por análise lingüística o processo reflexivo (epilingüístico) dos sujeitos-aprendizes, em relação à movimentação de recursos textuais, lexicais e gramaticais, no que tange ao contexto de produção e aos gêneros veiculados, no processo de leitura, de construção e de reescrita textuais (PERFEITO, 2005).

Por isso, sugerimos que a gramática seja abordada contextualizadamente em dois momentos: 1) no processo de leitura, com a mobilização dos recursos lingüístico-expressivos, para a coprodução de sentidos; e 2) no momento da reescrita ou refacção textual, ocasião de análise da produção de sentidos e de maior abordagem de aspectos formais e da coerência. Nos dois momentos, há que se considerar as marcas lingüísticas (do gênero) e enunciativas (do sujeitoautor), de acordo com o arranjo composicional e com o contexto de produção. 
Desse modo, consideramos que o aluno em contato com diferentes gêneros discursivos em organização curricular progressiva, no processo de leitura (e de escrita), tem a oportunidade de experienciar a pluralidade de textos que circulam em distintas esferas de atividade humana, com diversidade de conteúdo temático, de construção composicional e de estilo.

Com estudos teóricos, sobretudo, de Bakhtin (1992); Rojo (2000), Barbosa (2003), Rojo e Cordeiro (2004) Dolz e Schneuwly (1996; 2004), após processo de diagnóstico realizado pelo projeto em salas de aula de várias escolas, e a constatação de que grande parte dos professores de ensino fundamental tem pouca clareza do "porquê" e do "como" ensinar com gêneros discursivos, Perfeito $(2005 \text {, p. } 61)^{1}$ elabora no artigo "Concepcỗes de linguagem: teorias subjacentes e ensino de língua portuguesa" uma proposta, partindo de idéias de Barbosa (2003), a ser utilizada na análise de textos de variados gêneros, no espaço escolar:

- Contexto de producão e relação autor/leitor/texto - observação de aspectos relativos ao/à: autor/enunciador, destinatário, provável objetivo, local e época de publicação e de circulação; exploração das inferências, das críticas, das emoções suscitadas; criação de situações-problema e de transformações, veiculadas a efeitos de sentido do texto etc. - Conteúdo temático - temas que são tratados em textos pertencentes ao gênero em questão.

- Organização geral (construção composicional) - a estrutura, o arranjo textual.

- Marcas lingüisticas e enunciativas - características do gênero (lingüísticas) e do autor (enunciativas), o qual veicula seu texto, fundamentalmente, em determinado gênero.

\footnotetext{
${ }^{1}$ Mais especificamente, a autora entende que, na veiculação de um gênero discursivo, o sujeito enuncia, com sua expressividade, em determinadas condições de produção, as marcas regulares do gênero relativamente estabilizadas - ou o arranjo textual / ou marcas lingüísticas - e outras, mais específicas. Daí, na análise de um texto de determinado gênero, as marcas lingüístico-enunciativas serem abordadas de forma indissociada. Não deixa de observar, também, a possibilidade de hibridização / transformação de gêneros.
} 
Com tal embasamento teórico-prático, em 2006, ${ }^{2}$ retornamos às escolas, com a proposta de intervenção. $\mathrm{Na}$ escola em que desenvolvemos o trabalho, ${ }^{3}$ embora a professora com quem havia sido feito o diagnóstico, em uma $4^{a}$ série tivesse se aposentado no início de 2005, ela se dispôs a participar do processo de intervenção, a partir da leitura/análise da transcrição de suas aulas gravadas. O interesse veio, também, da direção e da supervisão do estabelecimento de ensino. Esta última acompanhou/acompanha todo o processo de formação continuada.

A participação da professora foi imprescindível nas discussões iniciais, por dar abertura para que seu trabalho fosse analisado pelo grupo de professoras de ensino fundamental ( $1^{\mathrm{a}}$ a $4^{\mathrm{a}}$ série), e, principalmente, por questionar sua própria prática em atividades de análise lingüística. Assim, propiciou ao grupo a avaliação do encaminhamento de sua prática, no que se refere ao ensino gramatical, no interior de diferentes concepções de linguagem. Inclusive, a percepção de como estão situados os gêneros discursivos na visão interacionista da linguagem e, sobretudo, de como planejar, via gêneros, as atividades de análise lingüística, após uma primeira leitura do texto de Perfeito (2005).

Nessa tarefa, empenhamo-nos (2 pesquisadoras, 4 professoras e a coordenadora) durante seis meses, no ano de 2006, em reuniões quinzenais, para análise crítica da transcrição e estudo, discussão, abordagem prática de variados gêneros de diferentes ordens, e, ao final, o grupo de professoras decidiu que, no ano seguinte, trabalhariam no sentido de elaborar um currículo cujo eixo seriam os gêneros discursivos.

A primeira etapa, em conjunto, já havíamos atingido: as professoras haviam entrado em contato (e exerceram discussões e

\footnotetext{
${ }^{2}$ Uma das autoras fez o diagnóstico na escola, no final de 2003, com gravação e transcrição das aulas cuja análise teve como resultado uma monografia de conclusão de Especialização. No ano de 2005, ausentou-se do projeto enquanto os demais membros do grupo continuavam o diagnóstico, transcrição e discussão dos resultados em outras escolas. Em 2006, ingressou no mestrado e ao Projeto, dando prosseguimento à fase de intervenção.

${ }^{3}$ As autoras do artigo em pauta intervêm especificamente em um estabelecimento de ensino da região sul de Londrina.
} 
práticas) com a noção de gênero, de suas características básicas e de seu processo de modificação/hibridização, a começar de sua identificação de agrupamento em ordens - não fechadas, flexíveis (DOLZ; SCHNEUWLY, 1996, 2004), levando em conta domínio social em que circulam, as capacidades de linguagem envolvidas e a construção composicional que o caracteriza.

Variados gêneros (notícia, reportagem, fábula, lenda, narrativa curta infantil, poema, comunicado, receita, carta pessoal, propaganda, textos de divulgação científica, crônica, etc.) foram analisados junto às professoras, em termos de agrupamento em ordens, condições de produção, tema, construção composicional e marcas lingüísticoenunciativas, em confronto com suas práticas/abordagens em sala de aula. Conhecimento intuitivo e científico entrelaçavam-se em uma experiência enriquecedora para todos os envolvidos no processo.

É importante lembrar que, neste primeiro momento, o estudo das marcas lingüístico-enunciativas do gênero com o texto escrito (objetivo do projeto) foi priorizado no processo de construção de sentidos, levando-se em conta suas características. Paralelamente a isto, novas aulas de produção/refacção textual foram gravadas, com o objetivo de abordar, contextualizadamente, o ensino gramatical em outro momento e atividade.

Para atingir o objetivo do grupo, no entanto, verificamos que se faz necessário acompanhar o planejamento e o desenvolvimento do trabalho prático para dirimir dúvidas sobre a abordagem do gênero como eixo de progressão e articulação curricular, integrando as atividades de leitura, de análise lingüística e de produção/refacção textual. E, nesse sentido, propiciar maiores discussões sobre o ensino gramatical contextualizado. Este é nosso desafio para o ano de 2007, a princípio, com a semana de planejamento das aulas com as professoras.

$\mathrm{Na}$ semana referida, as professoras decidiram que a primeira unidade a ser abordada seria a fábula (por ser um gênero estudado em todas as séries iniciais e, ainda, devido ao fato de dominarem tal gênero com maior profundidade). Sob esse aspecto, estamos acompanhandoas, desde a escolha, a "dosagem" e a abordagem dos textos nos dois primeiros ciclos do ensino fundamental. A perspectiva é, também, de trabalho com poema, lenda, narrativa com mito, conto de fadas, notícia, receita, poema-fábula, pequeno texto de divulgação científica, crônica infantil, literatura de cordel, classificado, etc., nas variadas séries. 
No artigo em pauta, apresentamos algumas sugestões de abordagem, a serem discutidas com as professoras, para efeito de trabalho em sala de aula (com as devidas reformulações / adequações e aprofundamentos), relativas ao conteúdo temático e às suas condições de produção, juntamente ao arranjo textual e às marcas lingüísticoenunciativas, no processo de exploração de aspectos pertinentes à narrativa com mito. No caso específico, narrativa cuja personagem seja o Saci Pererê.

\section{0 que é mito}

A palavra mito vem do grego e significa história ou palavra. Assim como as lendas, os mitos não têm autoria conhecida e explicam a existência do homem e os mistérios da natureza. Tratam de sentimentos básicos: paixão, amor, ódio e medo. Às vezes, mito e lenda são confundidos, porque os limites de cada um são tênues (GOMES, 2001).

Segundo Brandão (2000, p. 54),

Apesar dos aspectos fantasiosos, dos elementos fantásticos e aparentemente ilógicos que o povoam, o mito é verdade para o povo que o cultiva, está profundamente enraizado no seu tecido social, distinguindo-se, portanto, da lenda e sobretudo da superstição.

Mindlin ${ }^{4}$ (BRANDÃO, 2000) afirma que os indígenas não utilizam o termo lenda em suas narrativas por conceberem-na como desvinculada do povo, enquanto que o mito é o patrimônio cultural, constituindo-se num elemento de coesão social, de agregação e, em conseqüência, preservando-lhe a identidade.

Cascudo (1989) faz distinção entre lenda e mito pelo fator tempo-espaço, definindo o verbete lenda da seguinte maneira:

LENDA - "Episódio heróico ou sentimental com elemento maravilhoso ou sobre-humano, transmitido e conservado na tradição oral popular, localizável no espaço e no tempo [...]. Muito confundido com o mito, dele se distingue pela função e confronto. $\mathrm{O}$ mito pode

\footnotetext{
${ }^{4}$ Antropóloga Betty Mindlin, em entrevista às autoras do artigo Mito e tradição Indígena (BRANDÃO, 2000).
} 
ser um sistema de lendas, gravitando ao redor de um termo central com área geográfica mais ampla e sem exigência de fixação no tempo e no espaço."

O termo é, por vezes, utilizado de forma pejorativa para se referir às crenças comuns (consideradas sem fundamento objetivo ou científico) de diversas comunidades. No entanto, até acontecimentos históricos podem se transformar em mitos, se adquirirem uma determinada carga simbólica para uma dada cultura.

O pensamento mítico, conforme dissemos em relação à origem da palavra, teve início na Grécia, do séc. XXI ao VI a.C.. Nasceu do desejo de dominação do mundo, para afugentar o medo e a insegurança. A verdade do mito não obedece à lógica nem da verdade empírica, nem da verdade científica. O mito não é exclusividade de povos primitivos, nem de civilizações nascentes, mas existe em todos os tempos e culturas como componente indissociável da maneira humana de compreender a realidade. (OLIVEIRA, s/d).

Consideraremos, então, o gênero mito como narrativa de significação simbólica, transmitida de geração em geração e considerada verdadeira ou autêntica dentro de um grupo. Tal gênero, dessa forma, é caracterizado por narrativas que explicam a origem do mito.

No estudo em tela, porém, não abordaremos o gênero mito, mas uma narrativa - uma história curta - em que uma das personagens é um mito, ou seja, um gênero que denominaremos narrativa com mitos.

Para versar sobre a narrativa com mitos, faz-se importante - antes da análise específica de um texto deste gênero - a breve explicitação de alguns aspectos: as funções do mito; a caracterização do mito como personagem; o arranjo textual e as marcas lingüísticas (regulares) do gênero e a tipicidade do mito Saci Pererê.

\subsection{Funções do mito}

Os provérbios e as danças, os ritos e as anedotas, o artesanato e as superstições, os brinquedos e os remédios caseiros, entre outros tantos fatos, assim como o mito, existem, não por geração espontânea, mas para atender e responder às necessidades (intelectual, de lazer, religiosa, mágica, material, saúde, lúdica, existencial, etc.) de um grupo social local, regional ou nacional (ROCHA, 1996). 
O mito, portanto, é uma "primeira fala sobre o mundo", uma primeira atribuição de sentido, sobre a qual a imaginação exerce grande papel, e cuja função principal não é explicar a realidade, mas acomodar o homem ao mundo.

Claro está que mitos são símbolos, e como todo e, qualquer símbolo, encerram uma mensagem ou uma informação codificada, inteligivel apenas para os que conhecem o código, a decodificação. Alguns são universais, outros restringem-se a uma região, porém, todos são expressões da necessidade humana de registrar e transmitir uma descoberta, um conhecimento ou uma lição. (PEREIRA, 2001)

\subsection{Características do mito como personagem}

Cada mito tem características próprias e apresenta diferentes histórias. No Brasil, são conhecidos os da Mula-sem-cabeça, Curupira, Boitatá, Iara, Lobisomem, entre outros. Mula-sem-cabeça, por exemplo, é uma personagem monstruosa em que se transforma a mulher que namorou padres e foi amaldiçoada, e em noites de sexta-feira assombra pessoas da comunidade. Curupira é descrito como um anão com os pés voltados para trás, com a função de proteger as árvores e os animais, cujo rastro engana os caçadores para que se percam na floresta.

Boitatá aparece sob a forma de enorme serpente de fogo, que mata quem destrói as florestas. Iara tem as mesmas características das sereias, mulher da cintura para cima, peixe da cintura para baixo, com canto irresistível aos ouvidos dos homens, e os atrai para o fundo das águas, onde habita. Lobisomem é um homem aparentemente comum, que nas noites de lua cheia se transforma em um lobo e mata quem cruza o caminho, mas antes de amanhecer adquire forma humana novamente.

Esses mitos têm em comum, além das características físicas próprias, uma origem determinada ou uma função, algumas ações freqüentes das quais as pessoas precisam saber certas dicas para quebrar o encanto ou ficar livre de seus atos. A maioria possui origem indígena, quando não, sofreu diretamente sua influência.

Em suas aparições em diferentes regiões do Brasil, surgem também nomes variados: Boitatá (no sul - Baitatá, Batatá, Bitatá; no 
nordeste - Batatão e Biatatá; entre os índios - Mbaê-Tata); Caipora Curupira, Pai do Mato, Mãe do Mato, Caiçara, Anhangá, etc.; Iara Mãe d'água, Ipupiara, Uiara; Barba Ruiva - Uurué, Barba Nova, Cabeça Vermelha; Lobisomem (mito universal) - Licantropo, Quibungo, Capelobo, Kumacanga (Pará), Curacanga (Maranhão), Hatu-Runa (Equador), El Chupasangre (Colômbia); Mula-sem-cabeça - Burrinha do Padre, Burrinha, Mula Preta, Cavalo-sem-cabeça, Padre-sem-cabeça.

Ainda outros mitos brasileiros podem ser verificados, como o Boto, Caipora, Matinpereira (Martim Pereira), Negrinho do Pastoreiro, Barba Ruiva e o Saci Pererê.

\subsection{O arranjo textual e as marcas lingüísticas de narrativas com mitos}

As marcas do gênero narrativa com mitos são mobilizadas pelos enunciadores juntamente às marcas mais específicas - conforme explicitado anteriormente. Se observarmos narrativas cujas personagens são mitos, podemos identificar certas regularidades, denominadas marcas lingüísticas, algumas, evidentemente, próprias dos gêneros da ordem do narrar:

- enunciado de ações;

- ordenação dos eventos numa sucessão temporal e causal (ordem cronológica); imperfeito) e

- tempo verbal do mundo narrado (pretérito perfeito e

- presença do discurso direto, indireto e indireto livre.

O nome do autor (ou autores) da maioria das histórias que envolvem mitos, em geral, fica oculto, perdendo-se no tempo. Motivo pelo qual os fatos folclóricos são considerados anônimos.

As histórias envolvem a capacidade de mimesis de ação, através da criação de uma intriga no domínio do verossímil, como gênero pertencente ao agrupamento da ordem do narrar.

A determinação de tempo e espaço, em geral, não é relevante. Quando há indicação de tempo, ela é vaga, imprecisa, introduzida por expressões como "era uma vez", sem dizer com exatidão quando acontecem os fatos.

O autor, nesse sentido, pretende apenas expor uma situação/ fato central, desenrolada pelo mito. 
As personagens não são descritas com muitos detalhes, pois a maioria são mitos bastante conhecidos.

Tais narrativas apresentam uma solução ainda que momentânea para determinadas situações ocasionadas pela personagem mítica.

\section{Um mito tipicamente brasileiro: o Saci}

Cascudo (1976) registra que foi em fins do século XVIII que se deu a aparição do Saci, vindo do Sul, pelo Paraguai-Paraná, zona indicada como tendo sido o centro da dispersão dos Tupi-Guaranis. Outros afirmam que o Saci tenha surgido no século XIX. Concordam, porém, ao dizer tratar-se de uma evolução de um mito indígena ao qual foram acrescentadas contribuições de elementos africanos e europeus.

Assim, inicialmente chamar-se-ia Yaci Yaterê e seria um índio de uma só perna. Esse índio teria ganhado a cor negra como contribuição do africano e o nome de Saci. Daí teria o português the colocado um gorro vermelho. Entretanto, para alguns, originariamente o Saci possuía duas pernas perfeitas.

De região para região, de tempo em tempo, o Saci modifica sua aparência. Há relatos de Saci com calção ou mesmo nu, com duas pernas, de uma só perna ou com uma atrofiada.

Câmara Cascudo (1989) faz sua descrição como sendo:

pequeno negrinho, com uma só perna, carapuça vermelha na cabeça, que o faz. encantado, ágil, astuto, amigo de fumar cacbimbo, de entrançar as crinas dos animais, depois de extenuá-los em correrias, durante a noite, anuncia-se pelo assobio persistente e misterioso...

Como os demais mitos, o Saci assume diversas denominações, podendo ser Saci Pererê no Sul do país, Kaipora no Centro e Matintapereira ou Maty-Taperé ao Norte, além de Maty, Çaci, Saci, Pererê, Cererê, Saci-Saperê, Saci-trique, Saci-Seperê, SaciTaterê.

O Saci é considerado, para alguns autores, um representante da época da escravidão. Portanto, não seria por acaso que se apresenta 
com uma perna só, pois todos os escravos fugidos que eram recapturados passavam por muitas torturas. Segundo esses autores, a falta da perna, como algo que acontecia nesta época, passou para o folclore a partir das amas negras, ao contarem suas histórias para embalar as crianças brancas.

O termo Saci resulta do tupi-guarani "Çaa cy perereg". Vem do verbo pererek, pular. Daí a origem do nome Saci Pererê que, por não ter uma perna, anda aos pulos (revista Galileu, edição 89).

As traquinagens ocorridas, em especial na zona rural, são sempre atribuídas ao Saci. Apaga a luz do candeeiro, some a criança do berço, queima o arroz, azeda o feijão, faz desandar a massa do bolo, coloca insetos na comida, troca o sal pelo açúcar. À noite, dá nó na crina dos cavalos, rouba os ninhos das galinhas, deixa as porteiras abertas, assobia como o vento nas janelas e nas portas. Também invade casas, esconde objetos, assusta as crianças e causa insônias.

Dizem também que o Saci espera os transeuntes nas porteiras e em pontes para pedir-lhes fumo e fogo. Se os obtém, deixa o viajante em paz. Caso contrário, dá-lhe uma surra, assobia em seu ouvido até que fique surdo e depois monta na garupa do cavalo o qual dispara em correria durante toda a noite.

Contam alguns que onde se forma um redemoinho de vento com muita poeira (pé de vento) há um Saci. Para capturá-lo, deve-se jogar dentro dele um rosário ou uma peneira, e então, com cautela, engarrafá-lo. O Saci ficará invisível por alguns dias, para somente depois tornar-se aparente para o seu caçador. Dizem também que quem conseguir a carapuça do Saci ser-lhe-á senhor absoluto. Tudo fará o Saci para recuperar sua carapuça. Em algumas versões, ele pode tornarse invisível com o uso de sua carapuça vermelha. Rezar o Credo, para alguns, é o recurso mais eficaz para livrar-se do Saci Pererê (CAVALHEIRO, 2000).

Com o passar do tempo, a imagem do Saci rebelde e desordeiro foi amenizada e passou a ser um símbolo nacional. Um molequinho arteiro, perdendo seus poderes mágicos e sua agressividade.

Monteiro Lobato foi o responsável pela difusão do Saci Pererê por todo o Brasil. Primeiro, com a proposição de um debate sobre o Saci, publicado no jornal O Estado de São Paulo e compilado em forma de livro com o título "O Sacy-Perêrê - Resultado de um inquérito", em 1918. 
A idéia de reavivar o mito propondo um "inquérito" movimentou na época um grande número de pessoas predispostas a dar testemunho sobre sua existência. Essa personagem foi aproveitada por Monteiro Lobato nas aventuras ocorridas no Sítio do Pica-pau Amarelo.

Com o livro "O Saci", que descreve a captura de um Saci pelo Pedrinho, Lobato resgata para o mundo infantil o mito e populariza essa personagem, como uma entidade travessa. Conta que ele nascia em um local da floresta conhecida como "sacizeiros", constituída de bambuzais de onde só saia quando completasse sete anos e vivia até os setenta e sete. Surgem, então, de forma escrita, narrativas em que o mito passa a ser personagem das história.: as peripécias do Saci Pererê.

A partir da versão televisionada do "Sítio do Pica-pau Amarelo", as travessuras do Saci Pererê lhe garantiram popularidade em todo o país e fora dele.

O escritor, chargista e cartunista Ziraldo também criou a turma do Pererê, com personagens como: o coelho, o macaco, o tatu, o jaboti, a onça, a coruja, um indiozinho, duas meninas e dois caçadores.

O folclore teceu, então, em torno dessa personalidade inúmeros recontos, embora muitos deles não sejam comercialmente publicados. Como outros mitos, suas histórias fazem parte da tradição oral.

A seguir, apresentaremos a análise de um texto do gênero narrativa com mito: o Saci Pererê.

\section{$3 \mathrm{O}$ texto em análise}

\section{Saci Pererê}

Era uma vez uma velha que tinha por hábito, antes de deitar, preparar três cachimbos. Um ela pitava enquanto terminava os afazeres finais de arrumação da cozinha. Outro logo a seguir. E deixava o terceiro, costumeiramente em cima da taipa do fogão, para fumar depois de lavar os pés.

Acontece que, antes de fazer os preparativos finais para deitarse, ia para outros compartimentos da casa.

Começou a observar que todas as vezes que ia pitar o último cachimbo ele estava pela metade. Um dia resolveu ficar à espreita. Lá 
pelas tantas, o Saci senta-se na beirada do fogo e passa a cachimbar gostosamente o pito de barro.

- "Ele me paga"! - monologou a velha ...

Noutro dia, encheu de pólvora o cachimbo com uma brasa e dali a pouco foi aquele estouro. "O Saci ficou aturdido e quando eu cheguei para pegá-lo", contou a velha, "errou a porta, mas a janela estava destramelada e ele fugiu"...

"Nunca mais apareceu para fumar o meu cachimbo ..."

OLIVEIRA, João Rodrigues de. Folclore nacional: folclore, tradição, superstição. Curitiba: [s.n.], 1977. (Texto de Alceu M. Araújo, em sua homenagem)

O texto foi produzido por Alceu Maynard Araújo, que pela própria característica do gênero, não é o autor, mas quem fez o registro escrito. Vem reproduzido no livro "Folclore nacional: folclore, tradição, superstição", de João Rodrigues de Oliveira, publicado em 1977. A mesma história aparece no livro O Saci, de Monteiro Lobato (1993), tendo como narrador o tio Barnabé.

No livro, o texto em questão aparece na parte sobre superstição, junto a santos protetores de doenças, candomblé, ao número 13, umbanda e outros mitos como Iara, Mula sem Cabeça, Boitatá, Lobisomem, Curupira, Negrinho do Pastoreio.

Alceu Maynard Araújo é professor e autor de vários livros sobre folclore: "Folclore Nacional", "Antologia do Folclore Brasileiro", "Cultura Popular Brasileira", entre outros, em várias edições e volumes, a partir de 1960. As últimas versões foram lançadas pela editora Martins Fontes, em 2004.

O tema abordado é o próprio Saci, um dos mitos do folclore brasileiro. Personagem com características bem definidas e famosa por suas traquinagens.

No plano geral, a história em questão possui um narradorobservador que apresenta duas personagens (a velha e o Saci), as quais desenrolam uma seqüência de ações, mas sem se determinar o espaço.

- Parágrafo 1 e 2: apresentação de uma personagem (a velha) e de suas atitudes usuais;

- Parágrafo 3: introdução do conflito (começou a observar que, todas as vezes que ia pitar o último cachimbo, ele estava pela metade...); o desdobramento do conflito (um dia resolveu ficar à 
espreita); a apresentação de uma personagem específica (Lá pelas tantas, o Saci ...); a evocação de sua atitude e sentimento (passa a cachimbar gostosamente o pito de barro);

- Parágrafo 5: o acontecimento notável (clímax) "encheu de pólvora o cachimbo"; a resolução da complicação (ele fugiu).

- Parágrafo 6: o comentário final "nunca mais voltou para fumar o meu cachimbo".

O $1^{\circ}$ parágrafo inicia-se com o pretérito imperfeito, tempo que remete ao mundo narrado e indica fatos contínuos ou ações freqüentes. A expressão "era uma vez" remete a um tempo indeterminado.

No segundo, a oração modalizadora "acontece que" revela uma atitude de justificativa do narrador, para poder comprovar como o Saci se apodera do cachimbo, sem que a velha veja, e assim introduz o conflito. $\mathrm{Na}$ seqüência, os verbos estão no pretérito imperfeito, continuando a apresentação de ações habituais.

Ao utilizar o verbo "começou" ( $3^{\circ}$ parágrafo), o narrador indica a mudança de estado (se a velha estava desatenta, nesse momento ela percebe que há algo "errado"), após a recorrência do fato que é salientada pela expressão "todas as vezes que". Ao utilizar o conectivo temporal "um dia", permite ao leitor um pressuposto de que finalmente a personagem tomou uma atitude. $\mathrm{O}$ uso desse conectivo tem o mesmo valor de "até que". Um novo circunstancializador temporal indefinido é mobilizado "lá pelas tantas" para apresentar a segunda personagem (o Saci) e o verbo "passa" introduz o pressuposto de que até então o Saci não estava fumando. O advérbio "gostosamente" revela a avaliação do narrador da forma de fumar do Saci. Com o pretérito perfeito, faz um retrospecto dos fatos até chegar ao acontecimento principal.

No discurso direto ( $4^{\circ}$ parágrafo), a utilização do tempo presente aponta a aproximação com o leitor. Há também uma mudança do tipo de narrador, a princípio observador ( $3^{a}$ pessoa), e finalizado em $1^{a}$ pessoa.

Com outro circunstancializador temporal "noutro dia", o $5^{\circ}$ parágrafo traz o ato notável. Interessante o narrador não utilizar adjetivos para caracterizar os fatos e personagens, nem mesmo para qualificar a proporção do estouro, escolhendo para isso um pronome demonstrativo "aquele estouro", que adquire uma função adjetiva. 
Chama, dessa forma, o leitor a compartilhar com ele o conhecimento de grandiosidade. O operador argumentativo "mas" orienta para a conclusão (fugiu).

E, no comentário final (o texto é concluído pela personagem e não pelo narrador), o circunstancializador "nunca mais" revela que o Saci não voltou a fumar o cachimbo. No entanto, o uso do verbo "aparecer" permite pressupor que a velha pode não ter ficado livre de outras traquinagens do Saci, como é característica de seu comportamento.

Mencionamos aqui alguns recursos mobilizados pelo autor na produção de sentidos, mas outros aspectos podem ser explorados, como: o uso de aspas, para indicar a fala da personagem; o uso de advérbios indicadores de atitude ou estado psicológico diante dos enunciados (costumeiramente, gostosamente); e do artigo indefinido um e definido $o$ outro, $o$ terceiro como elementos de coesão.

É também marca visível do autor o uso constante de expressões temporais para fazer a progressão no texto: $1^{\circ}$ parágrafo: antes de deitar, enquanto, logo a seguir, depois de. Parágrafo $2^{\circ}$ : antes de, um dia, lá pelas tantas. $5^{\circ}$ parágrafo: noutro dia, dali a pouco. $6^{\circ}$ parágrafo: nunca mais.

E, ainda, a utilização de linguagem popular, com termos e expressões característicos de certa comunidade (grupo social): destramelada, taipa, afazeres, pito, compartimentos, ficar à espreita.

\section{Proposta de trabalho}

Os alunos têm certo conhecimento de mitos sobre o qual podem se apoiar para ler/produzir narrativas. E o folclore pode se tornar importante elemento de criação de auto-estima, afirmação da personalidade e consolidação da cidadania, além de facilitar o aprendizado da linguagem.

$\mathrm{O}$ mito pertence originalmente às formas orais de comunicação (tanto que são poucos os registros escritos) e exige um conjunto de capacidades de linguagem da ordem do narrar.

O professor, como mediador entre o sujeito e o objeto de ensino, deve pensar em atividades seqüenciadas, a serem propostas/ abordadas, relativas a esse gênero. 
Para apontar caminhos aos professores, elaboramos uma seqüência de questionamentos que podem ser feitos aos alunos no processo de produção ou co-produção de sentidos, a fim de indicar alternativas de trabalho na leitura, produção e análise lingüística.

1) Sugestão de atividades de leitura e de análise lingüística

\section{- Conteúdo temático}

- O texto fala sobre o Saci, que é um mito. Você tem algum conhecimento sobre o Saci?

- Já ouviu falar sobre o aparecimento de algum?

- Como você o imagina?

- Pesquise sobre o Saci e sua origem.

- De acordo com o texto, como podemos definir o comportamento do Saci?

- Que outros mitos você conhece?

- A partir do título do livro no tema tratado.

- Qual a diferença entre mito, superstição e tradição? Procure com mais um colega, no dicionário/enciclopédia, estabelecer a diferença, por escrito, para posterior discussão em sala de aula.

- Contexto de produção e relação autor/leitor/texto

- Onde foi veiculado o texto?

- Quem provavelmente lê esse tipo de livro?

- Podemos encontrar livros como o mencionado com freqüência nas bibliotecas, livrarias? Existem versões atuais?

- O que podemos considerar como folclore?

- Quem são, provavelmente, as duas pessoas mencionadas, ao final do texto?

- Onde mais podemos encontrar textos como esse?

- Quem cria essas histórias?

- Há quanto tempo você acha que essas histórias são contadas?

- Arranjo textual

- O texto Saci Pererê é uma narrativa com um mito. Você reconhece uma indicação precisa da época em que os fatos acontecem? Por quê? 
- Onde você acha que a história acontece? Justifique sua resposta.

- Na narrativa com mitos, a descrição do lugar no qual ocorre a história é importante para que o leitor / ouvinte compreenda o acontecido? Justifique sua resposta.

- No texto lido, o narrador participa da história ou somente conta a história?

- Em quais parágrafos são apresentadas as personagens? Existe algum motivo para essa seqüência? nesse texto?

- Qual o sinal usado para marcar as falas das personagens

- Um acontecimento desencadeia o conflito/ a complicação da história. Qual é ele?

- Como o conflito foi resolvido?

- Identifique o parágrafo que apresenta um comentário da personagem.

- Marcas lingüistico-enunciativas.

- O que o uso de reticências indica no texto?

- O ato "de lavar os pés", mencionado no texto, se apresenta para você como:

( )o hábito próprio da personagem, que gostava de lavar os pés, antes de deitar.

( ) um costume de pessoas de uma época ou região que não possuíam facilidades para tomar banho, por isso lavavam apenas os pés.

( ) uma superstição da personagem.

- $\mathrm{O}$ autor utiliza expressões que indicam tempo. Assinale quais são essas expressões:

antes de, um, enquanto, outro, logo a seguir, terceiro, acontece que, depois de, um dia, lá pelas tantas, noutro dia, dali a pouco, nunca mais

- A palavra pagar tem o mesmo sentido na expressão "ele me paga", presente no texto, e na situação em que um amigo diz ao outro: "ele me paga o dinheiro que lhe empresto"? Por quê? 
- No texto, é usado o discurso direto, em que as falas são utilizadas para aproximar o leitor da personagem e vice-versa. Indique as passagens que contêm diálogos.

- Indique os verbos utilizados pelo narrador para apresentar a fala de alguma personagem. Identifique quem é a personagem que fala.

- Da relação abaixo, assinale os verbos que indicam a introdução da fala da personagem:

dizer, fazer, falar, andar, responder, correr, perguntar, afirmar, gritar, contar, anunciar, chorar

- Na frase final "nunca mais apareceu para fumar o meu cachimbo", quem pronuncia essas palavras: o narrador ou uma das personagens? Justifique sua resposta com elementos do texto.

- No primeiro e no segundo parágrafos, os verbos (pitava, terminava, deixava, ia) indicam:

( ) ações freqüentes

( ) uma condição ou uma coisa incerta

( ) uma ordem

- Na passagem: "lá pelas tantas, o Saci senta-se na beirada do fogo e passa a cachimbar gostosamente o pito de barro", em que tempo verbal estão conjugados os verbos?

- Esse tempo verbal é usado para indicar:

( ) uma ordem

( ) uma certeza, um fato dado como certo

( ) dúvida

- O Saci estava fumando, ao sentar-se na beirada do fogo? Justifique com elementos do texto.

- No $1^{\circ}$ parágrafo, o autor evita a repetição da palavra cachimbo, utilizando outros elementos para substituí-la. Identifique quais são as palavras utilizadas.

- As palavras "destramelada, taipa, afazeres, pito, compartimentos, ficar a espreita" são utilizadas com freqüência no dia-a-dia? Pesquise o significado dessas palavras no dicionário e justifique seu uso no texto. 
- "Noutro dia, encheu de pólvora o cachimbo com uma brasa e dali a pouco foi aquele estouro". O que significa "aquele" nesse contexto?

2) Produção de texto

Tendo por base a seqüência didática proposta por Dolz e Schneuwly (2004), sugerimos algumas atividades:

a) Elaboração de trabalhos para o domínio do gênero narrativas com mitos, via oficinas.

b) Produção de um texto ligado ao gênero escolhido, após a leitura e análise de variados textos do gênero, inclusive com diferenças de arranjo textual.

Oficina A - Identidade dos mitos ${ }^{5}$

Objetivo: conhecer as identidades de vários mitos e contar histórias em que apareçam.

I. Pedir para os alunos escreverem tudo o que entendem pela palavra mito (assuntos, personagens).

II. Apresentar uma lista de títulos para que assinalem aqueles que acham que é mito:

O lobo e o Cordeiro, a Mula-sem-Cabeça, Branca de Neve, Boitatá, Chapeuzinho Vermelho, Lobisomem, Curupira, A Bela Adormecida, Caipora.

III. Ouvir dos alunos, histórias que eles conhecem e o que sabem cujas personagens sejam mitos (informações complementares podem ser verificadas com passagens do livro O Saci, de Monteiro Lobato, pois todos esses mitos são descritos pelo autor).

IV. Distribuir um mito para cada grupo organizar a ficha da personagem: nome do mito, suas caraterísticas físicas e de comportamento, e seu retrato (os alunos podem desenhar).

V. Cada grupo cria uma história em que seu mito seja personagem.

${ }^{5}$ Fonte: GOMES, Ana Valeska Amaral (coord.). Ler e escrever, com muito prazer: a diversidade textual na alfabetização de jovens e adultos. Guia com dicas para uso da série de programas, com adaptações. 
Oficina $\mathrm{B}^{6}$ - Identidade do mito Saci Pererê

As atividades desta tarefa podem ser feitas em grupo ou individualmente.

I. Em uma folha de papel, pedir para o aluno escrever uma frase, um parágrafo ou um pequeno texto que represente o que ele pensa ou o lembra de ter lido ou ouvido sobre o Saci.

II. Ler três diferentes histórias sobre o mito Saci Pererê.

III.Comparar os três textos. Identificar as semelhanças e diferenças entre eles; para facilitar o trabalho, fazer uma tabela de duas colunas: uma para as semelhanças e outra para as diferenças.

for novidade.

IV. Assinalar nos textos, ou em um registro à parte, o que

Oficina C - Identificação do arranjo textual e marcas lingüísticas

I. Selecionar diferentes histórias (narrativas) com o mito, inclusive com diferenças composicionais.

II. Ler os textos, comparando as diferenças e semelhanças, quanto ao arranjo textual.

III. Analisar se a escolha do arranjo textual interfere no sentido que é produzido.

IV. Após a leitura de várias narrativas que envolvem mitos, indicar as caraterísticas que se repetem nessas histórias.

Oficina D - Atividade de criação textual

Neste caso, as atividades de autoria propostas pelos PCNs (1998) são mais indicadas, pois envolvem criação. A tarefa do sujeitoautor se torna mais complexa, porque precisa articular o que dizer (conteúdo) ao como dizer (estratégias, modos de dizer), segundo Perfeito (2005), considerando o gênero e todo o entendimento da pesquisa realizada.

Sugestão:

Narrar uma história cuja personagem seja o Saci Pererê, observando a:

\footnotetext{
${ }^{6}$ Fonte: http://wqsaci.vilabol.uol.com.br/WeQtSACI/Index.htm, com adaptações.
} 
- A progressão do texto, a retomada de sentidos e a relação entre as partes do texto.

- A criatividade no trato da história elaborada.

- Grafia correta das palavras e pontuação adequada.

\section{Considerações Finais}

Objetivamos apresentar aos professores aspectos teóricos e sugestões de transposição didática de narrativas com mitos brasileiros, no caso específico, a abordagem de uma narrativa com o mito Saci Pererê. E, neste contexto, o trabalho gramatical contextualizado. Não pretendemos esgotar o assunto ou dar receitas, mas contribuir para o processo de ensino-aprendizagem, de modo que os professores tenham parâmetros para planejar em suas aulas aspectos realmente relevantes, no sentido de oportunizar a ampliação de universo lingüístico-discursivo do aluno.

\section{Referências}

BAKHTIN, M. Estética da criação verbal. Trad. de M. M. E. G. Pereira. São Paulo: Martins Fontes, 1992.

BARBOSA, J. P. Receita. São Paulo: FTD, 2003. (Coleção Trabalhando com gêneros do discurso).

BRANDÃO, Helena N. Gêneros do discurso na escola: mito, conto, cordel, discurso político, divulgação científica. São Paulo: Cortez, 2000.

BRASIL. Parâmetros Curriculares Nacionais: língua portuguesa: terceiro e quarto ciclos. Brasília: MEC/SEF, 1998.

Parâmetros Curriculares Nacionais: língua portuguesa: primeiro e segundo ciclos. Brasília: MEC/SEF, 1997.

BRONCKART, Jean-Paul. Atividades de linguagem, textos e discursos: por um interacionismo sócio-discursivo. São Paulo: Educ, 1999. 
CASCUDO, Luís da Câmara. Dicionário do Folclore Brasileiro. v. 1 e 2. Rio de Janeiro: Edições de Ouro, 1989.

Geografia dos Mitos Brasileiros. 2. ed. Rio de Janeiro: José Olympio/MEC, 1976.

CAVAlHEIRO, Carlos Carvalho. Sociedade dos Observadores de Saci. Núcleo Caipira Regional de Sorocaba. Comissão Paulista de Folclore/ IBCC/UNESCO. 07.03.2000. Disponível em: <http:// www.sosaci.org/>. Acesso em: 12 fev. 2007.

CELANI, Maria Antonieta Alba. A relevância da lingüística aplicada na formulação de uma política educacional brasileira. In: FORTKAMP, M. B. M. e TOMITCH, L.M.B. (Org.) Aspectos de lingüistica aplicada. Estudos em homenagem ao professor Hilário Inácio Bohn. Florianópolis: Insular, 2000. p. 17-32.

DOLZ, B.; SCHNEWLY, D. Gêneros e progressão em expressão oral e escrita: elementos para reflexões sobre uma experiência suíça (francófona). In: Gêneros do oral e do escrito na escola. Trad. e org. Rojo, R.; Cordeiro, G. L.. Campinas: Mercado de Letras, 2004. p. 41-70.

Genres et progression en expression orale et écrite: eléments de réflexion à propos d'une expérience romande. Genebra, Suíça: Enjeux, 1996. p. 31-39. Trad. de Roxane Rojo (mimeo.).

GERALDI, João Wanderley. Portos de passagem. São Paulo: Martins Fontes, 2003.

GOMES, Ana Valeska Amaral (coord.). Ler e escrever, com muito prazer: a diversidade textual na alfabetização de jovens e adultos: guia com dicas para uso da série de programas. Brasília: MEC, 2001. 96p. (Rádio Escola). Disponível em: <http://www.unopar.br/bibli01/ catalogos.htm>. Acesso em: 15 set. 2006.

LOBATO, Monteiro. O Saci. 54. ed. São Paulo: Brasiliense, 1993. 
MOITA LOPES, L. P. Oficina de Lingüistica Aplicada: a natureza social e educacional dos processos de ensino-aprendizagem de língua. Campinas: Mercado de Letras, 2000.

OLIVEIRA, Cristina G. Machado. O que é mito? [s/d.] Disponível em: $<$ http://www. filosofiavirtual.pro.br/mitologia.htm>. Acesso em: 15 fev. 2007.

OLIVEIRA, João Rodrigues de. Folclore nacional: folclore, tradição, superstição. Curitiba: [s.n.], 1977.

PEREIRA, Franz Kreüther. Painel de lendas \& mitos da Amazônia: trabalho premiado ( $1^{\circ}$ lugar) no concurso "Folclore Amazônico 1993" da Academia Paraense de Letras. Belém: <http://www.tiosan.com/, 2001>. 92p. Disponível em: <http://www.unopar.br/bibli01/ catalogos.htm>. Acesso em: 15 fev. 2007.

PERFEITO, Alba M. Concepções de linguagem, teorias subjacentes e ensino de língua portuguesa. In: Concepsões de linguagem e ensino de língua Portuguesa (Formação de professores EAD 18). v. 1. Maringá: EDUEM, 2005. p. 27-79.

PORTO, Idelma M. N. Lendas: uma abordagem prática. In. I CONGRESSO NACIONAL DE LITERATURA E INTERAÇÃO, 2006, Maringá, UEM, 2006. (no prelo).

ROJO, Roxane Helena Rodrigues. Modos de transposição dos PCNs às práticas de sala de aula: progressão curricular e projetos. In:

(Org.) A prática de linguagem em sala de aula: praticando os PCNs. São Paulo: EDUC; Campinas: Mercado de Letras, 2000. p. 27-38.

.; CORDEIRO, G.S. Apresentação: gêneros orais e escritos como objetos de ensino: modo de pensar, modo de fazer. In: SCHNEUWLY, B.; DOLZ, J.. Gêneros orais e escritos na escola. Trad. e org. de Rojo, R. e Cordeiro, S. Campinas: Mercado de Letras, 2004. p. $7-18$. 
ROCHA, Sebastião. Folclore: roteiro de pesquisa. Belo Horizonte: [s.n.], 1996.

SACI: do imaginário ao real. Disponível em: <http:// wqsaci.vilabol.uol.com.br/WeQtSACI/Index.htm>. Acesso em: 15 fev. 2007.

TRAVAGLIA, L.C. Gramática e interação: uma proposta para o ensino de gramática no $1^{\circ}$ e $2^{\circ}$ graus. São Paulo: Cortez, 2000. 